\title{
Low-dose real-time X-ray imaging with nontoxic double perovskite scintillators
}

\author{
Wenjuan Zhu', Wenbo Ma $\mathbb{1}^{1}$, Yirong Su', Zeng Chen², Xinya Chen', Yaoguang Ma', Lizhong Bai', Wenge Xiao $\mathbb{D}^{1}$, \\ Tianyu Liu', Haiming Zhu $\mathbb{D}^{2}$, Xiaofeng Liu', Huafeng Liu', Xu Liu (1) ${ }^{1}$ and Yang (Michael) Yang (1)
}

\begin{abstract}
X-rays are widely used in probing inside information nondestructively, enabling broad applications in the medical radiography and electronic industries. X-ray imaging based on emerging lead halide perovskite scintillators has received extensive attention recently. However, the strong self-absorption, relatively low light yield and lead toxicity of these perovskites restrict their practical applications. Here, we report a series of nontoxic double-perovskite scintillators of $\mathrm{Cs}_{2} \mathrm{Ag}_{0.6} \mathrm{Na}_{0.4} \mathrm{In}_{1-y} \mathrm{Bi}_{y} \mathrm{Cl}_{6}$. By controlling the content of the heavy atom $\mathrm{Bi}^{3+}$, the X-ray absorption coefficient, radiative emission efficiency, light yield and light decay were manipulated to maximise the scintillator performance. A light yield of up to $39,000 \pm 7000$ photons/MeV for $\mathrm{Cs}_{2} \mathrm{Ag}_{0.6} \mathrm{Na}_{0.4} \mathrm{In}_{0.85} \mathrm{Bi}_{0.15} \mathrm{Cl}_{6}$ was obtained, which is much higher than that for the previously reported lead halide perovskite colloidal $\mathrm{CsPbBr}_{3}(21,000$ photons/MeV). The large Stokes shift between the radioluminescence (RL) and absorption spectra benefiting from self-trapped excitons (STEs) led to a negligible selfabsorption effect. Given the high light output and fast light decay of this scintillator, static X-ray imaging was attained under an extremely low dose of $\sim 1 \mu \mathrm{Gy}_{\text {air }}$ and dynamic $X$-ray imaging of finger bending without a ghosting effect was demonstrated under a low-dose rate of $47.2 \mu \mathrm{Gy} \mathrm{air}_{\mathrm{r}} \mathrm{s}^{-1}$. After thermal treatment at $85^{\circ} \mathrm{C}$ for $50 \mathrm{~h}$ followed by $\mathrm{X}$-ray irradiation for $50 \mathrm{~h}$ in ambient air, the scintillator performance in terms of the RL intensity and X-ray image quality remained almost unchanged. Our results shed light on exploring highly competitive scintillators beyond the scope of lead halide perovskites, not only for avoiding toxicity but also for better performance.
\end{abstract}

\section{Introduction}

$\mathrm{X}$-ray imaging has been actively utilised in the fields of industrial material inspection, medical diagnosis and scientific research ${ }^{1-10}$. Low-dose irradiation, high stability and high spatial resolution are generally regarded as the most important characteristics for X-ray imaging ${ }^{11,12}$. Current Xray imaging systems mostly rely on scintillators that are capable of converting X-ray photons into visible photons that are then detected by a photodiode array ${ }^{13-15}$. Conventional scintillators, such as thallium-doped caesium iodide $(\mathrm{CsI}: \mathrm{Tl})^{16,17}$ and cerium-doped lutetium-aluminium garnet

\footnotetext{
Correspondence: Yang (Michael) Yang (yangyang15@zju.edu.cn)

${ }^{1}$ State Key Laboratory of Modern Optical Instrumentation, College of Optical

Science and Engineering, International Research Center for Advanced

Photonics, Zhejiang University, Hangzhou, Zhejiang, China

${ }^{2}$ Center for Chemistry of High-Performance \& Novel Materials, department of

Chemistry, Zhejiang University, Hangzhou, Zhejiang, China

These authors contributed equally: Wenjuan Zhu, Wenbo Ma
}

$(\mathrm{LuAG}: \mathrm{Ce})^{18}$, usually require expensive and time-consuming synthesis, which poses a major challenge for device processability. Unlike conventional scintillator materials, the emerging lead halide perovskites for X-ray detectors are starting to show attractive merits of facile fabrication, fast response and good spatial resolution ${ }^{19-26}$. However, the relatively low X-ray light yield, lead toxicity ${ }^{27-29}$ and instability greatly limit their applications in high-end X-ray imaging featuring low-dose exposure, hazard-free manufacturing, real-time monitoring and robustness.

Fortunately, previous efforts have discovered many efficient lead-free emitters, e.g., double-perovskite ${ }^{30-32}$, copper $^{33-35}$ and bismuth $(\mathrm{Bi})^{36-38}$-based metal halides, which hold potential for X-ray scintillators. Very recently, $\mathrm{Rb}_{2} \mathrm{CuBr}_{3}{ }^{33}$ and $\mathrm{Cs}_{2} \mathrm{NaTbCl}_{6}{ }^{39}$ were shown to be scintillators with high light yield. However, the long decay time and strong afterglow impede their use in realising high

\section{(c) The Author(s) 2020}

(c) (i) Open Access This article is licensed under a Creative Commons Attribution 4.0 International License, which permits use, sharing, adaptation, distribution and reproduction c. in any medium or format, as long as you give appropriate credit to the original author(s) and the source, provide a link to the Creative Commons license, and indicate if changes were made. The images or other third party material in this article are included in the article's Creative Commons license, unless indicated otherwise in a credit line to the material. If material is not included in the article's Creative Commons license and your intended use is not permitted by statutory regulation or exceeds the permitted use, you will need to obtain permission directly from the copyright holder. To view a copy of this license, visit http://creativecommons.org/licenses/by/4.0/. 
a
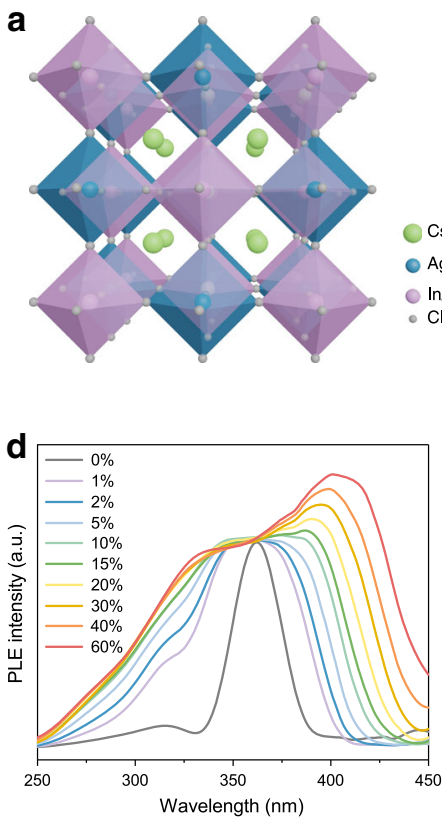

b

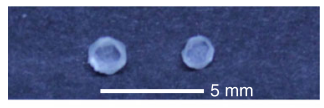

CSs

- Ag/Na

$\because \mathrm{Cl} / \mathrm{B}$

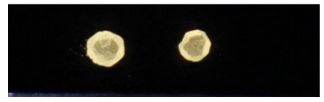

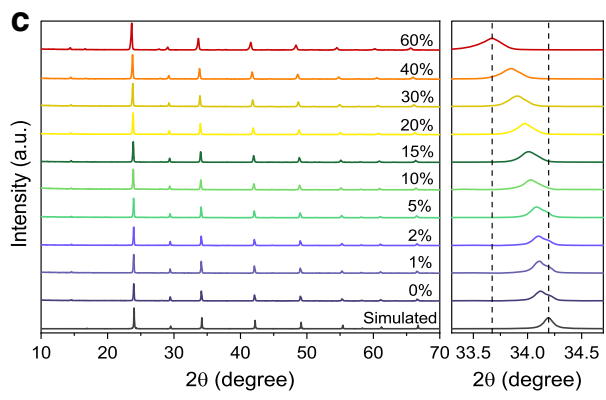
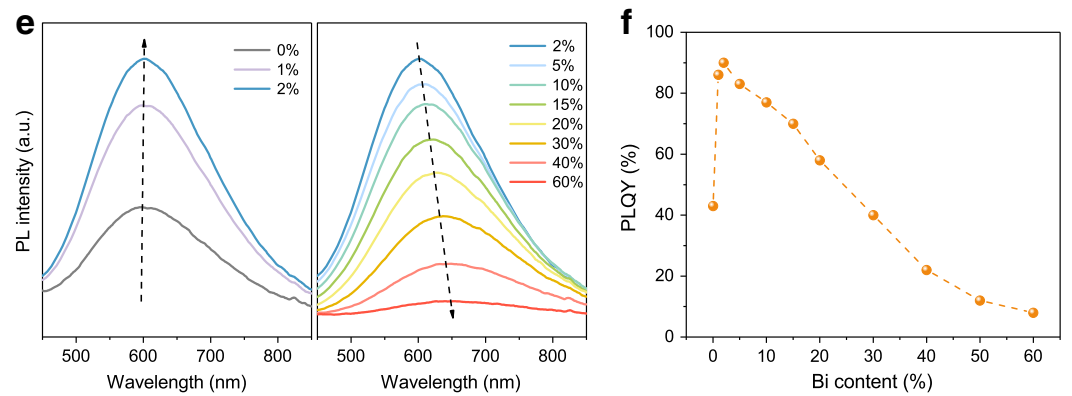

Fig. 1 Crystal structure and photoluminescence $(\mathrm{PL})$ characterisation of $\mathrm{Cs}_{2} \mathrm{Ag}_{0.6} \mathrm{Na}_{0.4} \mathbf{I n}_{1-\mathrm{y}} \mathrm{Bi}_{\mathbf{y}} \mathrm{Cl}_{6}$. a Crystal structure of the double perovskite. b Photographs of $\mathrm{Cs}_{2} \mathrm{Ag}_{0.6} \mathrm{Na}_{0.4} \mathrm{In}_{0.85} \mathrm{Bi}_{0.15} \mathrm{Cl}_{6}$ single crystals under daylight and UV light excitation. $\mathbf{c}$ XRD patterns (left) and selected diffraction peaks near $34^{\circ}$ (right) of $\mathrm{Cs}_{2} \mathrm{Ag}_{0.6} \mathrm{Na}_{0.4} \mathrm{In}_{1-\mathrm{y}} \mathrm{Bi}_{\mathrm{y}} \mathrm{Cl}_{6}$ with different $\mathrm{Bi}^{3+}$ contents. $\mathbf{d}$ Photoluminescence excitation (PLE) spectra and e PL spectra of $\mathrm{Cs}_{2} \mathrm{Ag}_{0.6} \mathrm{Na}_{0.4} \mathrm{In}_{1-\mathrm{y}} \mathrm{Bi}_{\mathrm{y}} \mathrm{Cl}_{6}$ powder with different $\mathrm{Bi}^{3+}$ contents. f Photoluminescence quantum yield (PLQY) of $\mathrm{Cs}_{2} \mathrm{Ag}_{0.6} \mathrm{Na}_{0.4} \mathrm{In}_{1-\mathrm{y}} \mathrm{Bi}_{\mathrm{y}} \mathrm{Cl}_{6}$ powder with various $\mathrm{Bi}^{3+}$ contents

contrast X-ray imaging, especially for X-ray computed tomography (CT). Another limitation of $\mathrm{Rb}_{2} \mathrm{CuBr}_{3}$ is that its emission wavelength is in the blue region, which does not match the peak response of the common camera. Hence, the development of nontoxic halide scintillators with merits of high light yield, fast light decay and wellmatched emission wavelength remains a challenge. In this article, a series of nontoxic double perovskites of $\mathrm{Cs}_{2} \mathrm{Ag}_{0.6} \mathrm{Na}_{0.4} \mathrm{In}_{1-\mathrm{y}} \mathrm{Bi}_{\mathrm{y}} \mathrm{Cl}_{6}$ single crystals with variable $\mathrm{Bi}^{3+}$ content were prepared. The introduction of a moderate amount of $\mathrm{Bi}^{3+}$ not only improves the radioluminescence (RL) output but also accelerates the radiative recombination, leading to a high scintillator light yield of 39,000 \pm 7000 photons $/ \mathrm{MeV}$ and fast light decay for $\mathrm{Cs}_{2} \mathrm{Ag}_{0.6^{-}}$ $\mathrm{Na}_{0.4} \mathrm{In}_{0.85} \mathrm{Bi}_{0.15} \mathrm{Cl}_{6}$. The nontoxic scintillator delivers long-term stability under continuous thermal treatment and X-ray irradiation in ambient air. With a $\mathrm{Cs}_{2} \mathrm{Ag}_{0.6^{-}}$ $\mathrm{Na}_{0.4} \mathrm{In}_{0.85} \mathrm{Bi}_{0.15} \mathrm{Cl}_{6}$ wafer as the scintillator, high-quality static and dynamic images of different objects were obtained under low-dose X-ray irradiation.

\section{Results}

Commonly, the double-perovskite structure $\mathrm{Cs}_{2} \mathrm{~B}^{\mathrm{I}-}$ $\mathrm{B}^{\mathrm{III}} \mathrm{Cl}_{6}$ is regarded as a homologue of the $\mathrm{ABX}_{3}$-type perovskite, in which the $\mathrm{B}$ sites are replaced by equal amounts of monovalent and trivalent cations ${ }^{40}$. Herein, $\mathrm{B}^{\mathrm{I}}$ is occupied by $\mathrm{Ag}^{+}$and $\mathrm{Na}^{+}$with different alloying ratios.
By means of $\mathrm{Na}^{+}$doping in $\mathrm{Cs}_{2} \mathrm{AgInCl}_{6}$, the parityforbidden transition is partly broken, and the electronic dimensionality is reduced as well ${ }^{31}$. Therefore, bright near-white light emission via radiative recombination of self-trapped excitons (STEs) of $\mathrm{Cs}_{2} \mathrm{Ag}_{1-x} \mathrm{Na}_{\mathrm{x}} \mathrm{InCl}_{6}(x=0.2$, $0.4,0.6,0.8)$ single crystals is obtained. The optimised $\mathrm{Na}^{+}$content $x$ is determined to be 0.4 , for which the photoluminescence quantum yield (PLQY) reaches $43 \%$ (Supplementary Fig. S1).

$\mathrm{Bi}$ is an earth-abundant and green element, and it has an even larger atomic number than the widely used heavy $\mathrm{X}$-ray absorbing elements of $\mathrm{Pb}$ and $\mathrm{TI}$; hence, we introduced partial $\mathrm{Bi}^{3+}$ to replace $\mathrm{In}^{3+}$, initially for the purpose of increasing the X-ray absorption efficiency ${ }^{41,42}$. The powder X-ray diffraction (PXRD) patterns of a series of $\mathrm{Cs}_{2} \mathrm{Ag}_{0.6} \mathrm{Na}_{0.4} \mathrm{In}_{1-\mathrm{y}} \mathrm{Bi}_{\mathrm{y}} \mathrm{Cl}_{6}$ (Fig. 1c) samples confirm that the pure double-perovskite phase is the same as $\mathrm{Cs}_{2} \mathrm{AgInCl}_{6}$, which belongs to space group $\mathrm{Fm}-3 m$ with a face-centred cubic structure. It is worth mentioning that the PXRD peaks shift to a lower diffraction angle with increasing $\mathrm{Bi}^{3+}$ content due to the larger ionic radius of $\mathrm{Bi}^{3+}(103 \mathrm{pm})$ than that $\operatorname{~of~}^{3+}(80 \mathrm{pm})$, which can be clearly observed in the zoomed-in figure (right side of Fig. 1c). In addition, the scanning electron microscopy-energy-dispersive spectrometry (SEM-EDS) results (Supplementary Table S2) of six averaged random spots on the testing sample demonstrate that the final chemical compositions of 
$\mathrm{Cs}_{2} \mathrm{Ag}_{0.6} \mathrm{Na}_{0.4} \mathrm{In}_{1-\mathrm{y}} \mathrm{Bi}_{\mathrm{y}} \mathrm{Cl}_{6}$ agree with the designed ratios. All the above analyses suggest that alloyed compounds of $\mathrm{Cs}_{2} \mathrm{Ag}_{0.6} \mathrm{Na}_{0.4} \mathrm{In}_{1-\mathrm{y}} \mathrm{Bi}_{\mathrm{y}} \mathrm{Cl}_{6}$ are successfully synthesised, whose chemical components change regularly, depending on the $\mathrm{Bi} / \mathrm{In}$ ratio.

Interestingly, in addition to the expected enhancement of the X-ray absorption, the luminescence properties of the alloyed double perovskites can also be tuned by $\mathrm{Bi}^{3+}$ alloying. The photoluminescence excitation (PLE) peak near $362 \mathrm{~nm}$ becomes more distinct and broader as the $\mathrm{Bi}^{3+}$ content increases (Fig. 1d), which is consistent with the steady-state absorption spectra (Supplementary Fig. S2). To evaluate the absorption band tail width of $\mathrm{Cs}_{2} \mathrm{Ag}_{0.6} \mathrm{Na}_{0.4} \mathrm{In}_{1-\mathrm{y}} \mathrm{Bi}_{\mathrm{y}} \mathrm{Cl}_{6}$, we calculated the Urbach energy $\left(E_{\mathrm{U}}\right)$ from the plotted straight fitting lines, and the corresponding values are given (Supplementary Fig. S2). Compared with $\mathrm{Cs}_{2} \mathrm{Ag}_{0.6} \mathrm{Na}_{0.4} \mathrm{InCl}_{6}$, the $E_{\mathrm{U}}$ of the $\mathrm{Bi}^{3+}$-doped perovskites significantly decreases, demonstrating that the band tail can be effectively suppressed because of further breaking of the parity-forbidden transition by the incorporated $\mathrm{Bi}^{3+43-45}$. When introducing more $\mathrm{Bi}^{3+}$, the absorption peak at $362 \mathrm{~nm}$ widens gradually and becomes less clear, and its intensity increases and is finally saturated in agreement with the PLE spectra, suggesting multiple absorption states that are widely distributed. The incorporated $\mathrm{Bi}^{3+}$ contributes to the valence-band structure by introducing shallow states right above the valence-band maximum of $\mathrm{Cs}_{2} \mathrm{Ag}_{0.6^{-}}$ $\mathrm{Na}_{0.4} \mathrm{In}_{1-\mathrm{y}} \mathrm{Bi}_{\mathrm{y}} \mathrm{Cl}_{6}{ }^{31}$ and forming a hyperfine energy level ${ }^{30}$, leading to broad absorption and excitation. Meanwhile, the absorption edges redshift as the $\mathrm{Bi} / \mathrm{In}$ ratio increases, and the bandgap $\left(E_{\mathrm{g}}\right)$ values were calculated from Tauc plots (Supplementary Fig. S3), demonstrating that the bandgap is monotonically decreasing ${ }^{46}$. Figure $1 \mathrm{e}$ shows the PL spectra of $\mathrm{Cs}_{2} \mathrm{Ag}_{0.6} \mathrm{Na}_{0.4} \mathrm{In}_{1-\mathrm{y}} \mathrm{Bi}_{\mathrm{y}} \mathrm{Cl}_{6}$ as a function of $\mathrm{Bi}^{3+}$ content. The PL intensity rapidly intensifies when the $\mathrm{Bi}^{3+}$ concentration increases from 0 to $2 \%$ and then weakens with further doping of $\mathrm{Bi}^{3+}$, obtaining the highest PLQY of $90 \%$ (Fig. 1f). Meanwhile, the PL peak redshifts from $605 \mathrm{~nm}$ to $652 \mathrm{~nm}$ due to the gradually narrowed bandgap caused by the $\mathrm{Bi}^{3+}$ substitution of $\mathrm{In}^{3+}$, in agreement with the absorption spectra. Apparently, the PL and absorption spectra overlap for this double-perovskite system is negligible. The large Stokes shift avoids the self-absorption effect that is detrimental to the output of scintillation light ${ }^{14}$. Both the outstanding PL efficiency and negligible self-absorption of $\mathrm{Cs}_{2} \mathrm{Ag}_{0.6^{-}}$ $\mathrm{Na}_{0.4} \mathrm{In}_{1-\mathrm{y}} \mathrm{Bi}_{\mathrm{y}} \mathrm{Cl}_{6}$ imply that these materials have the potential to be good scintillators.

The light decay time is another figure of merit for scintillators. The TRPL of $\mathrm{Cs}_{2} \mathrm{Ag}_{0.6} \mathrm{Na}_{0.4} \mathrm{In}_{1-\mathrm{y}} \mathrm{Bi}_{\mathrm{y}} \mathrm{Cl}_{6}$ was obtained by the TCSPC method pumped with a femtosecond laser $(400 \mathrm{~nm},<300 \mathrm{fs}, 1 \mathrm{MHz})$. As shown in Supplementary Fig. S4, the decay curve of $\mathrm{Cs}_{2} \mathrm{Ag}_{0.6} \mathrm{Na}_{0.4} \mathrm{InCl}_{6}$ can be fitted by a biexponential function, giving a fast decay process $(\sim 1 \mathrm{~ns})$ and a slower decay process $(2.8 \mu \mathrm{s})$, which is assigned to the forbidden STE emission ${ }^{30}$. To investigate the origin of the fast decay process, the TRPL of the STE-emission band (we used a filter to selectively collect the light signal from $700 \mathrm{~nm}$ to $800 \mathrm{~nm}$ ) was monitored, and it still showed distinct fast decay (Supplementary Fig. S5), excluding the possibility of band-to-band radiative recombination. This fast component gradually vanishes with the incorporation of $\mathrm{Bi}^{3+}$. Hence, the fast decay process $(\sim 1 \mathrm{~ns})$ may be assigned to the defect trapping process ${ }^{30,45}$ since $\mathrm{Bi}^{3+}$ can passivate defects ${ }^{31}$. In addition, when collecting the TRPL with different time resolutions (4ps/16 ps/512 ps), the fast decay process becomes unobvious when the time resolution is $512 \mathrm{ps}$ (Supplementary Fig. S5), indicating that this ultrafast process cannot be detected with low time resolution. With increasing $\mathrm{Bi}^{3+}$ content, the lifetime of the slow component gradually shortens to the nanosecond level, which is superior to that of the current commercial CsI: $\mathrm{Tl}^{16}$, demonstrating the great potential for dynamic real-time $\mathrm{X}$-ray imaging. We reason that the breaking of the parityforbidden transition induced by $\mathrm{Bi}^{3+}$ doping results in improved radiative recombination kinetics; therefore, the lifetime becomes shorter.

To assess the scintillation property, a series of $\mathrm{Cs}_{2} \mathrm{Ag}_{0.6} \mathrm{Na}_{0.4} \mathrm{In}_{1-\mathrm{y}} \mathrm{Bi}_{\mathrm{y}} \mathrm{Cl}_{6}$ were tested under X-ray illumination. Figure 2a shows a plausible mechanism of X-ray scintillation in the lead-free halide double perovskites. The radiation energy is first absorbed by the heavy atoms of the double perovskites mainly through the photoelectric effect and inelastic Compton scattering, ejecting massive hot electrons; then, these electrons thermalise on an ultrafast timescale and are captured by luminescent centres $^{47,48}$. The high PLQY of our double-perovskite ensures that once electrons transfer to the recombination centre, the ultimate radiative emission is very efficient. To accurately measure the $\mathrm{RL}$, equimolecular $\mathrm{Cs}_{2} \mathrm{Ag}_{0.6^{-}}$ $\mathrm{Na}_{0.4} \mathrm{In}_{1-\mathrm{y}} \mathrm{Bi}_{\mathrm{y}} \mathrm{Cl}_{6}$ powder with various $\mathrm{Bi}$ ratios were compressed into compact wafers, and then, these wafers were closely attached to the circular window of an integrating sphere with a fixed distance to the $\mathrm{X}$-ray source. The corresponding RL spectra were recorded by a fibrecoupled spectrometer (Fig. 2b). Figure 2c shows photographs of $\mathrm{Cs}_{2} \mathrm{Ag}_{0.6} \mathrm{Na}_{0.4} \mathrm{In}_{0.85} \mathrm{Bi}_{0.15} \mathrm{Cl}_{6} \mathrm{SCs}$ and powder under $\mathrm{X}$-ray excitation, yielding strong and uniform lightyellow emission. Figure $2 \mathrm{~d}$ shows that the scintillation output has a nonmonotonic relation with the $\mathrm{Bi}$ ratio. It first increases, reaches the peak intensity at $15 \% \mathrm{Bi}^{3+}$, and then drops as the $\mathrm{Bi}^{3+}$ content further increases, which is mainly attributed to the collective effect of the X-ray absorption efficiency (Fig. 2g) and radiative emission efficiency that can be reflected by the PLQY (Fig. 1f). As we anticipated, the calculated X-ray attenuation efficiency 


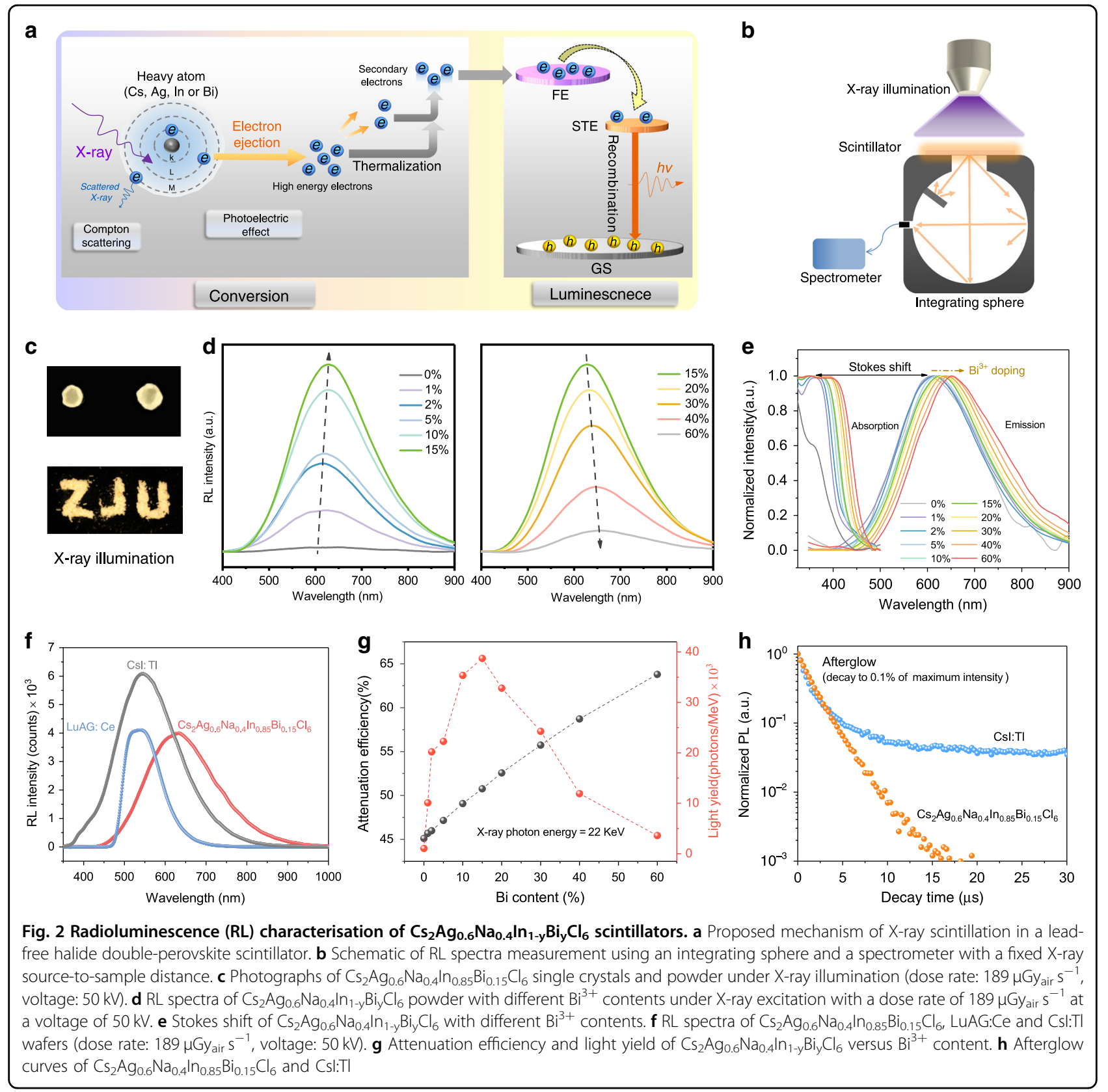

of $\mathrm{Cs}_{2} \mathrm{Ag}_{0.6} \mathrm{Na}_{0.4} \mathrm{In}_{1-\mathrm{y}} \mathrm{Bi}_{\mathrm{y}} \mathrm{Cl}_{6}$ enhances monotonically with $\mathrm{Bi}^{3+}$ doping because of the large atomic number of $\mathrm{Bi}^{3+}$ (Fig. 2g). Herein, when the $\mathrm{Bi}^{3+}$ content is increased from 0 to $2 \%$, both the PLQY and X-ray absorption of $\mathrm{Cs}_{2} \mathrm{Ag}_{0.6} \mathrm{Na}_{0.4} \mathrm{In}_{1-\mathrm{y}} \mathrm{Bi}_{\mathrm{y}} \mathrm{Cl}_{6}$ improve, leading to a rapid increase in the $\mathrm{RL}$ intensity. With further doping of $\mathrm{Bi}^{3+}$ from $2 \%$ to $15 \%$, the near-linear improvement of the $\mathrm{X}$-ray absorption dominates the slowly declining radiative emission efficiency, as manifested by the PLQY, resulting in continuous enhancement of the RL intensity. With $\mathrm{Bi}^{3+}$ doping greater than $15 \%$, the contribution of rapidly decreased PLQY exceeds that of the increased X-ray absorption efficiency of $\mathrm{Bi}^{3+}$, and the overall RL intensity diminishes. The shapes of the RL spectra are consistent with those of the corresponding PL spectra, indicating that the last step of an X-ray scintillation event is the same as the PL process, that is, they both emit light through STEs. One unique feature of STE emission is that the absorption and RL peak have a large Stokes shift, leading to negligible self-absorption, while a $\mathrm{Pb}$-based perovskite scintillator, e.g., $\mathrm{CsPBBr}_{3}$, has a very small Stokes shift due to its direct bandgap ${ }^{4}$. This large Stokes shift is generally favourable for any emitters but particularly desirable for scintillators since scintillators are very thick to ensure 
sufficient absorption of X-rays, but the scintillations are usually weak ${ }^{14}$. As shown in Supplementary Fig. S6, the integrated $\mathrm{RL}$ intensity of $\mathrm{Cs}_{2} \mathrm{Ag}_{0.6} \mathrm{Na}_{0.4} \mathrm{In}_{0.85} \mathrm{Bi}_{0.15} \mathrm{Cl}_{6}$ has a linear response to the $\mathrm{X}$-ray dose rate, highlighting its suitability for $\mathrm{X}$-ray contrast imaging.

Equivalent to the PLQY, the light yield (LY) of a scintillator is regarded as the internal X-ray-to-photon conversion efficiency, which can be measured as the ratio of the total emitted photon number to the absorbed Xray energy ${ }^{47}$. Theoretically, the LY is governed by the relation $\mathrm{LY}=10^{6} \times \mathrm{SQ} /\left(\beta \mathrm{E}_{\mathrm{g}}\right)$, where $\beta$ is a constant related to the host structure. As mentioned above, Eg slightly decreases with increasing $\mathrm{Bi}^{3+}$ content, which is a negligible factor for the $\mathrm{LY}$ in $\mathrm{Cs}_{2} \mathrm{Ag}_{0.6} \mathrm{Na}_{0.4} \mathrm{In}_{1-\mathrm{y}} \mathrm{Bi}_{\mathrm{y}} \mathrm{Cl}_{6}$. Hence, both the transfer efficiency $\mathrm{S}$ of hot-electron energy and the photoluminescence quantum yield $\mathrm{Q}$ (PLQY) govern the LY. In an attempt to quantify the RL light yield, we selected a commercial LuAG:Ce scintillator as a reference, whose light yield is $22,000 \pm 4000$ photons $/ \mathrm{MeV}$. To unify the absorbed X-ray energies of these two kinds of scintillator, the attenuation efficiencies of LuAG: Ce and $\mathrm{Cs}_{2} \mathrm{Ag}_{0.6} \mathrm{Na}_{0.4} \mathrm{In}_{0.85} \mathrm{Bi}_{0.15} \mathrm{Cl}_{6}$ as a function of thickness at an X-ray photon energy of $22 \mathrm{keV}$ were calculated, since the major X-ray photon energy of our tube is $22 \mathrm{keV}$ (Supplementary Fig. S7). Based on this relation curve, a $\mathrm{Cs}_{2} \mathrm{Ag}_{0.6} \mathrm{Na}_{0.4} \mathrm{In}_{0.85^{-}}$ $\mathrm{Bi}_{0.15} \mathrm{Cl}_{6}$ wafer with a 0.4-mm thickness and a LuAG:Ce wafer with a $0.11-\mathrm{mm}$ thickness were fabricated, and the corresponding RL spectra were recorded (Fig. 2f). In such circumstances, LuAG:Ce and $\mathrm{Cs}_{2} \mathrm{Ag}_{0.6} \mathrm{Na}_{0.4} \mathrm{In}_{0.85}$ $\mathrm{Bi}_{0.15} \mathrm{Cl}_{6}$ have the same $\mathrm{X}$-ray absorption cross sections, and therefore, the light output can be fairly compared. Finally, $\mathrm{Cs}_{2} \mathrm{Ag}_{0.6} \mathrm{Na}_{0.4} \mathrm{In}_{0.85} \mathrm{Bi}_{0.15} \mathrm{Cl}_{6}$ delivers a light yield of 39,000 \pm 7000 photons per $\mathrm{MeV}$, comparable with that of commercial CsI:Tl and much higher than that of the previously reported lead halide perovskite colloidal $\mathrm{CsPbBr}_{3}(21,000 \text { photons } / \mathrm{MeV})^{3}$. In addition, the light yields of $\mathrm{Cs}_{2} \mathrm{Ag}_{0.6} \mathrm{Na}_{0.4} \mathrm{In}_{1-\mathrm{y}} \mathrm{Bi}_{\mathrm{y}} \mathrm{Cl}_{6}$ for various $\mathrm{Bi}^{3+}$ contents are given in Fig. $2 \mathrm{~g}$, whose evolution trend corresponds well with the RL output intensity. It is noted that the trend of the scintillator light yield with the $\mathrm{Bi}^{3+}$ doping ratio is not exactly the same as that of the PLQY; $\mathrm{Cs}_{2} \mathrm{Ag}_{0.6} \mathrm{Na}_{0.4} \mathrm{In}_{0.85} \mathrm{Bi}_{0.15} \mathrm{Cl}_{6}$ has the highest scintillation light yield, while $\mathrm{Cs}_{2} \mathrm{Ag}_{0.6} \mathrm{Na}_{0.4} \mathrm{In}_{0.98} \mathrm{Bi}_{0.02} \mathrm{Cl}_{6}$ has the best PLQY. This highlights the fact that optimisation of the scintillator performance cannot always follow the PLQY results since the PLQY only reflects the efficiency of the last step of a scintillation event, that is, the radiative emission of the thermalized electrons. In addition to the PLQY, the transfer efficiency $\mathrm{S}$ of hotelectron energy also plays a decisive role in the LY. Owing to the high atomic number of $\mathrm{Bi}$, we speculate that there is a tight radius of the hot-electron distribution around $\mathrm{Bi}^{3+}$ in $\mathrm{Cs}_{2} \mathrm{Ag}_{0.6} \mathrm{Na}_{0.4} \mathrm{In}_{1-\mathrm{y}} \mathrm{Bi}_{\mathrm{y}} \mathrm{Cl}_{6}$, which is beneficial to hot-electron energy transfer ${ }^{48}$. The LY value is maximised when the $\mathrm{Bi}^{3+}$ doping is $15 \%$ due to the collective effect of $\mathrm{S}$ and $\mathrm{Q}$, and the $\mathrm{SQ}$ product is optimised under this circumstance. Another interesting discovery is that the optimised $\mathrm{Cs}_{2} \mathrm{Ag}_{0.6} \mathrm{Na}_{0.4} \mathrm{In}_{0.85^{-}}$ $\mathrm{Bi}_{0.15} \mathrm{Cl}_{6}$ scintillator shows strong $\mathrm{X}$-ray absorption efficiency from $\sim 36 \mathrm{keV}$ to $60 \mathrm{keV}$, which is the region for common medical digital radiography (Supplementary Fig. S8). Another important parameter for scintillators is the afterglow, which can reduce the signal-to-noise ratio (SNR) of the X-ray imaging. To obtain high contrast imaging without lag, it is always desirable to reduce the afterglow, especially for $\mathrm{CT}$ imaging. As shown in Fig. $2 \mathrm{~h}$, the luminance signal of $\mathrm{Cs}_{2} \mathrm{Ag}_{0.6} \mathrm{Na}_{0.4} \mathrm{In}_{0.85} \mathrm{Bi}_{0.15} \mathrm{Cl}_{6}$ decays to $0.1 \%$ at $\sim 16 \mu \mathrm{s}$. This low afterglow significantly outperforms that of the previous $\mathrm{Rb}_{2} \mathrm{CuBr}_{3}$ (2.72\%o @ $20 \mathrm{~ms})^{33}$ and is much lower than that of the widely used scintillator CsI:Tl (1.5\%@ @ $3 \mathrm{~ms})$, demonstrating the great potential of $\mathrm{Cs}_{2} \mathrm{Ag}_{0.6} \mathrm{Na}_{0.4} \mathrm{In}_{0.85} \mathrm{Bi}_{0.15} \mathrm{Cl}_{6}$ for realtime $\mathrm{X}$-ray imaging and medical $\mathrm{CT}$ applications.

To implement X-ray imaging with $\mathrm{Cs}_{2} \mathrm{Ag}_{0.6} \mathrm{Na}_{0.4} \mathrm{In}_{0.85^{-}}$ $\mathrm{Bi}_{0.15} \mathrm{Cl}_{6}$ as a scintillator, a homemade optical system was built, as illustrated in Fig. $3 \mathrm{a}$. $\mathrm{Cs}_{2} \mathrm{Ag}_{0.6} \mathrm{Na}_{0.4} \mathrm{In}_{0.85} \mathrm{Bi}_{0.15} \mathrm{Cl}_{6}$ wafers with different thicknesses $(0.1 \mathrm{~mm}, 0.2 \mathrm{~mm}, 0.4 \mathrm{~mm}$ and $0.6 \mathrm{~mm}$ ) were tested for X-ray imaging performance. The X-ray images of the standard test-pattern plate given in Fig. 3c demonstrate that the spatial resolution decreases with thickening wafer due to the increased optical crosstalk caused by light scattering. To quantify the spatial resolution, the modulation transfer function (MTF) was calculated using slanted-edge images ${ }^{49}$ (Supplementary Fig. S9). As shown in Fig. 3d, the spatial resolution (which is defined as the spatial frequency value at $\mathrm{MTF}=0.2$ ) is determined to be $4.3 \mathrm{lp} \mathrm{mm}^{-1}, 3.2 \mathrm{lp} \mathrm{mm}^{-1}, 2.3 \mathrm{lp} \mathrm{mm}^{-1}$ and $1.4 \mathrm{lp} \mathrm{mm}{ }^{-1}$ for $\mathrm{Cs}_{2} \mathrm{Ag}_{0.6} \mathrm{Na}_{0.4} \mathrm{In}_{0.85} \mathrm{Bi}_{0.15} \mathrm{Cl}_{6}$ wafers with thicknesses of $0.1 \mathrm{~mm}, 0.2 \mathrm{~mm}, 0.4 \mathrm{~mm}$ and $0.6 \mathrm{~mm}$, respectively, which are consistent with the values from the $\mathrm{X}$-ray images of the standard test-pattern plate. The spatial resolution of the $\mathrm{Cs}_{2} \mathrm{Ag}_{0.6} \mathrm{Na}_{0.4} \mathrm{In}_{0.85} \mathrm{Bi}_{0.15} \mathrm{Cl}_{6}$ wafer with a 0.1-mm thickness is comparable with that of a Se directtype X-ray imager $\left(4.8 \mathrm{lp} \mathrm{mm}^{-1} \text { at MTF }=0.2\right)^{2,50}$. There is no doubt that further decreasing the thickness of the scintillator wafer can help improve the spatial resolution of $\mathrm{X}$-ray imaging, but a larger dose rate will be needed to produce a sufficient scintillating light signal when taking real-time imaging ${ }^{51}$. It is also worth mentioning that the spatial resolution can be further enhanced if the scintillator screen is closely attached to the CMOS panel since the optical crosstalk will be minimised in this case. However, with such an optical configuration, the field of view (FOV) is restricted by the size of the very expensive CMOS chip, while with our optical setup, we can view large objects such as human fingers with a $13.2-\mathrm{mm} \times 13.2-\mathrm{mm}$ CMOS chip. 

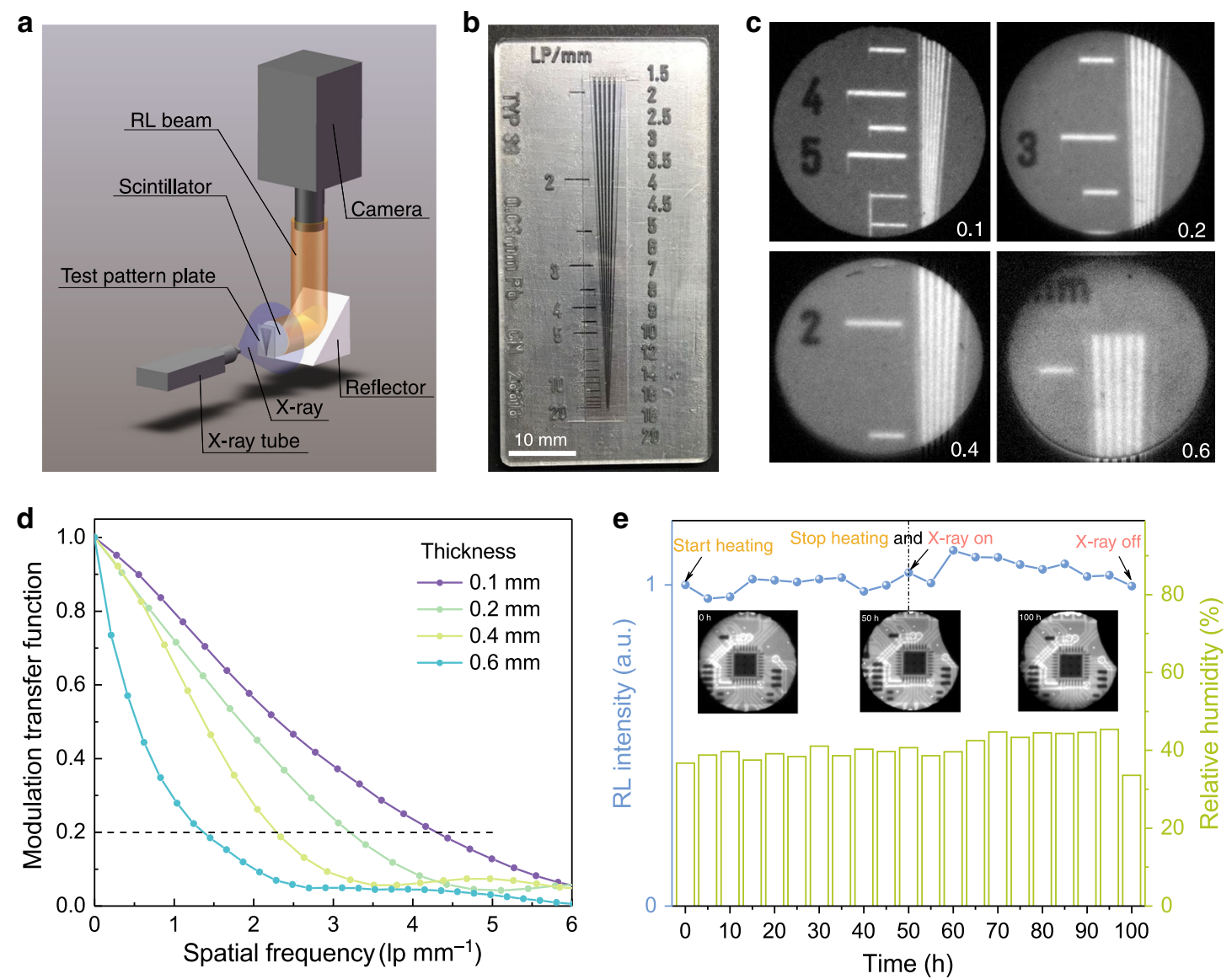

Fig. 3 X-ray imaging based on $\mathrm{Cs}_{2} \mathrm{Ag}_{0.6} \mathrm{Na}_{0.4} \mathrm{n}_{0.85} \mathrm{Bi}_{0.15} \mathrm{Cl}_{6}$ scintillator wafers with different thicknesses. a Schematic of the $X$-ray imaging system. b Photograph of the standard X-ray test-pattern plate. $\mathbf{c}$ X-ray images of the test-pattern plate based on $\mathrm{Cs}_{2} \mathrm{Ag}_{0.6} \mathrm{Na}_{0.4} \mathrm{In}_{0.85} \mathrm{Bi}_{0.15} \mathrm{Cl}_{6}$ wafers with different thicknesses (dose rate: $189 \mu \mathrm{Gy}_{\text {air }} \mathrm{s}^{-1}$, voltage: $50 \mathrm{kV}$ ). $\mathbf{d}$ Corresponding MTF curves of $\mathrm{Cs}_{2} \mathrm{Ag}_{0.6} \mathrm{Na}_{0.4} \mathrm{In}_{0.85} \mathrm{Bi}_{0.15} \mathrm{Cl}_{6}$ wafers with different thicknesses. e Integrated RL intensity of $\mathrm{Cs}_{2} \mathrm{Ag}_{0.6} \mathrm{Na}_{0.4} \mathrm{In}_{0.85} \mathrm{Bi}_{0.15} \mathrm{Cl}_{6}$ under thermal treatment for $50 \mathrm{~h}$ at $85^{\circ} \mathrm{C}$ followed by $\mathrm{X}$-ray illumination for another $50 \mathrm{~h}$ (dose rate: $12 \mu \mathrm{Gy}_{\text {air }} \mathrm{s}^{-1}$, voltage: $50 \mathrm{kV}$ ). The moisture level was also recorded, and the RL was measured with an integrating sphere. The inset shows X-ray images of a circuit board acquired at three different stages ( $0 \mathrm{~h}, 50 \mathrm{~h}$ and $100 \mathrm{~h}$ ) with a dose rate of $189 \mu \mathrm{Gy} \mathrm{yar} \mathrm{s}^{-1}$ at a voltage of $50 \mathrm{kV}$

The environmental, thermal and $\mathrm{X}$-ray radiation stability of the $\mathrm{Cs}_{2} \mathrm{Ag}_{0.6} \mathrm{Na}_{0.4} \mathrm{In}_{0.85} \mathrm{Bi}_{0.15} \mathrm{Cl}_{6}$ scintillator regarding the RL intensity and $\mathrm{X}$-ray image quality was systematically investigated. XRD patterns of $\mathrm{Cs}_{2} \mathrm{Ag}_{0.6^{-}}$ $\mathrm{Na}_{0.4} \mathrm{In}_{0.85} \mathrm{Bi}_{0.15} \mathrm{Cl}_{6}$ (Supplementary Fig. S10) measured after long-term exposure to humid ambient air indicate its high structural stability, which outperforms that of the known lead-based perovskites. The irradiation stability and thermostability of $\mathrm{Cs}_{2} \mathrm{Ag}_{0.6} \mathrm{Na}_{0.4} \mathrm{In}_{0.85} \mathrm{Bi}_{0.15} \mathrm{Cl}_{6}$ under ambient air were further examined. As shown in Fig. 3e, the RL intensity shows no obvious degradation under thermal treatment for $50 \mathrm{~h}$ at $85^{\circ} \mathrm{C}$ followed by continuous X-ray irradiation for another $50 \mathrm{~h}$ (Fig. 3e). The $\mathrm{X}$-ray images of a circuit board acquired at three specific time points $(0 \mathrm{~h}, 50 \mathrm{~h}$ and $100 \mathrm{~h})$ can hardly be distinguished from each other (inset of Fig. 3e). In addition, the MTF values of the X-ray images acquired at $0 \mathrm{~h}, 50 \mathrm{~h}$ and $100 \mathrm{~h}$ show only a slight variation (Supplementary Fig. S11). All the above analyses provide evidence of the excellent feasibility of applying the $\mathrm{Cs}_{2} \mathrm{Ag}_{0.6} \mathrm{Na}_{0.4} \mathrm{In}_{0.85^{-}}$ $\mathrm{Bi}_{0.15} \mathrm{Cl}_{6}$ scintillator in pervasive environments.

Based on the optimised composition and thickness, a wafer of $\mathrm{Cs}_{2} \mathrm{Ag}_{0.6} \mathrm{Na}_{0.4} \mathrm{In}_{0.85} \mathrm{Bi}_{0.15} \mathrm{Cl}_{6}$ with a $0.1-\mathrm{mm}$ thickness and a $5-\mathrm{cm}$ diameter was prepared. SEM images of the wafer surface present its compactness and homogeneity (Fig. 4b). Utilising this wafer, we obtained X-ray images of the test-pattern plate under different doses of radiation (Fig. 4e), and the corresponding MTF results give resolutions ranging from $1.5 \mathrm{lp} \mathrm{mm}^{-1}$ to $4.4 \mathrm{lp} \mathrm{mm}^{-1}$ (Supplementary Fig. S12). This result demonstrates our scintillator's capability to acquire high-resolution imaging under an extremely low dose of $\sim 1 \mu \mathrm{Gy}_{\text {air }}$, which is, to the best of our knowledge, the lowest dose requirement for perovskite-based X-ray imaging. The integrated RL 

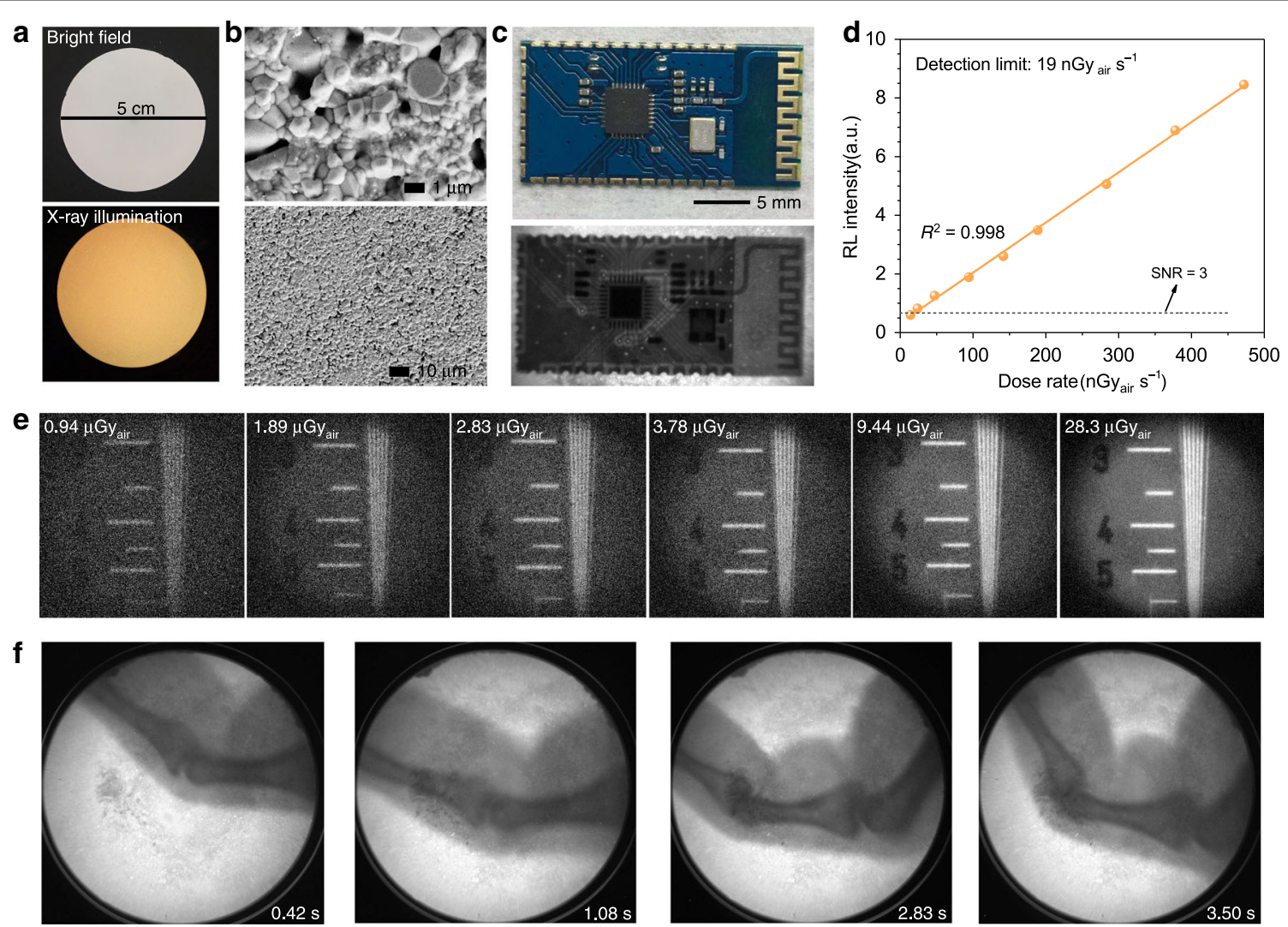

Fig. 4 Real-time and low-dose X-ray imaging with $\mathrm{Cs}_{2} \mathrm{Ag}_{0.6} \mathrm{Na}_{\mathbf{0 . 4}} \mathbf{I n}_{\mathbf{0 . 8 5}} \mathrm{Bi}_{0.15} \mathrm{Cl}_{6}$ scintillator wafers. a Photographs of a $\mathrm{Cs}_{2} \mathrm{Ag}_{0.6} \mathrm{Na}_{0.4} \mathrm{In}_{0.85} \mathrm{Bi}_{0.15} \mathrm{Cl}_{6}$ wafer under daylight and X-ray illumination (dose rate: $47.2 \mu \mathrm{Gy} \mathrm{yair}^{-1} \mathrm{~s}^{-1}$, voltage: $50 \mathrm{kV}$ ). b SEM images of the wafer surface. c Photograph of a circuit board (top) and its $\mathrm{X}$-ray image (below) (dose rate: $47.2 \mu \mathrm{Gy} \mathrm{yair} \mathrm{s}^{-1}$, voltage: $50 \mathrm{kV}$ ). $\mathbf{d} \mathrm{RL}$ intensity of $\mathrm{Cs}_{2} \mathrm{Ag}_{0.6} \mathrm{Na}_{0.4} \mathrm{In}_{0.85} \mathrm{Bi}_{0.15} \mathrm{Cl}_{6}$ measured at low-dose rates. The detection limit is derived from the fitting curve as the value when the SNR equals 3 (voltage: $50 \mathrm{kV}$ ). e X-ray images of the test-pattern plate acquired under different $\mathrm{X}$-ray doses (voltage: $50 \mathrm{kV}$ ). $\mathbf{f}$ Real-time X-ray images of finger bending (dose rate: $47.2 \mu \mathrm{Gy}$ air $\mathrm{s}^{-1}$, voltage: $50 \mathrm{kV}$ )

intensity of $\mathrm{Cs}_{2} \mathrm{Ag}_{0.6} \mathrm{Na}_{0.4} \mathrm{In}_{0.85} \mathrm{Bi}_{0.15} \mathrm{Cl}_{6}$ measured in the low-dose rate range presents an excellent linear response to the X-ray dose rate (Fig. $4 \mathrm{~d}$ ). The detection limit derived from the fitting curve when the SNR equals 3 is $19 \mathrm{nGy}_{\text {air }} \mathrm{s}^{-1}$, which is much lower than the typical medical imaging dose. To assess the feasibility of using the $\mathrm{Cs}_{2} \mathrm{Ag}_{0.6} \mathrm{Na}_{0.4} \mathrm{In}_{0.85} \mathrm{Bi}_{0.15} \mathrm{Cl}_{6}$ scintillator for dynamic realtime X-ray imaging, a video of finger bending (Supplementary Video 1) was obtained under a low-dose rate of $47.2 \mu \mathrm{Gy}_{\text {air }} \mathrm{s}^{-1}$, which exhibits a distinct phase contrast without a ghosting effect. The randomly selected X-ray images from the video at different time points show obvious biological tissue phase contrast and clear joint details (Fig. 4f). Figure 4c and Supplementary Fig. S13 are high-quality X-ray images of different circuit boards with various electronic components. An X-ray image of the complete test-pattern plate is shown in Supplementary Fig. S14. Considering these $\mathrm{X}$-ray imaging demonstrations, the $\mathrm{Cs}_{2} \mathrm{Ag}_{0.6} \mathrm{Na}_{0.4} \mathrm{In}_{0.85} \mathrm{Bi}_{0.15} \mathrm{Cl}_{6}$ scintillator qualifies as a potential candidate for low-dose real-time X-ray imaging.

\section{Discussion}

In conclusion, we developed a nontoxic $\mathrm{Cs}_{2} \mathrm{Ag}_{0.6^{-}}$ $\mathrm{Na}_{0.4} \mathrm{In}_{0.85} \mathrm{Bi}_{0.15} \mathrm{Cl}_{6}$ double-perovskite scintillator, which exhibits not only a high light yield but also long-term stability under continuous thermal treatment and X-ray irradiation. High-resolution X-ray image attained under a low dose of $\sim 1 \mu \mathrm{Gy}_{\text {air }}$ and distinct real-time imaging of finger bending demonstrate its great potential for X-ray imaging technology. Our results reveal the huge potential in exploring scintillators beyond lead halide perovskites, not only for avoiding toxic elements but also for achieving higher performance.

\section{Methods}

\section{Sample fabrication and characterisation}

A series of $\mathrm{Cs}_{2} \mathrm{Ag}_{1-\mathrm{x}} \mathrm{Na}_{\mathrm{x}} \mathrm{In}_{1-\mathrm{y}} \mathrm{Bi}_{\mathrm{y}} \mathrm{Cl}_{6}$ single crystals were prepared by a slightly modified hydrothermal reaction ${ }^{28}$. First, $2 \mathrm{mmol}$ of $\mathrm{CsCl}$ (99.9\%, Xi'an Polymer Light Technology Corp.) was dissolved in $10 \mathrm{ml}$ of a $10 \mathrm{M} \mathrm{HCl}$ (AR, Sinopharm) solution, followed by the addition of 1-x mol $\mathrm{AgCl}$ (99.999\%, Aldrich), x mol $\mathrm{NaCl}$ (99.99\%, Aladdin), 
1-y mol $\mathrm{InCl}_{3}$ (99.999\%, Aldrich) and y $\mathrm{mol} \mathrm{BiCl}_{3}(99.99 \%$, Macklin) at a certain ratio. The resulting mixture was transferred into a 50-ml Teflon autoclave and heated at $180^{\circ} \mathrm{C}$ for $12 \mathrm{~h}$. After cooling down to room temperature at $3^{\circ} \mathrm{Ch}^{-1}$, the precipitated millimetre-scale crystals were washed with isopropanol several times and dried at $60^{\circ} \mathrm{C}$ in a vacuum oven.

The scintillator wafers were compressed from ground powder of the resulting bulk crystals using a hydraulic press. Approximately $50-500 \mathrm{mg}$ of the powder was pressed at $15 \mathrm{MPa}$ for $5 \mathrm{~min}$ to form scintillator wafers with thicknesses in the range of $0.1-1 \mathrm{~mm}$. The thickness of the wafers was measured by a thickness gauge.

$\mathrm{X}$-ray diffraction (XRD) analyses were carried out after grinding crystals into fine powder on an X-pert Powder diffractometer (PANalytical B.V.) with $\mathrm{Cu}-\mathrm{K} \alpha$ radiation $(\lambda=0.15405 \mathrm{~nm})$ in the $2 \theta$ range from $10^{\circ}$ to $70^{\circ}$. Photoluminescence (PL) and PL excitation (PLE) spectra were recorded by an Edinburgh Instruments spectrofluorometer (FLS920). Scanning electron microscopy (SEM) images and energy-dispersive spectrometry (EDS) results were taken on a Hitachi SU8030 electron microscope equipped with an Oxford X-Max 20 silicon drift detector. Steady-state absorption spectra were detected using a home-built ultraviolet-visible spectrophotometer system equipped with an integrating sphere. PL quantum yield (PLQY) measurements were performed using an absolute photoluminescence measurement system (Hamamatsu Quantaurus-QY). Timeresolved photoluminescence (TRPL) decay kinetics were collected using a time-correlated single photon counting (TCSPC) module (PicoHarp 300) and an SPAD detector (IDQ, id100). The sample was excited by a femtosecond laser (Light Conversion Pharos, $400 \mathrm{~nm}$, $<300 \mathrm{fs}, 1 \mathrm{MHz}$ ). Afterglow curves were detected using the single shot transient digitiser (SSTD) technique. Radioluminescence (RL) spectra were measured by a fibre-coupled fluorescence spectrometer (Ocean Optics QE PRO) equipped with an integrating sphere and a fixed $\mathrm{X}$-ray source-to-sample distance.

\section{Light-yield measurement}

As is known, the light yield can be regarded as the ratio of the number of photons emitted from the luminescent sites to the total absorbed X-ray energy. First, we separately calculated the attenuation efficiency of LuAG:Ce $(22,000 \pm 4000$ photons $/ \mathrm{MeV})$ and $\mathrm{Cs}_{2} \mathrm{Ag}_{0.6} \mathrm{Na}_{0.4} \mathrm{In}_{0.85^{-}}$ $\mathrm{Bi}_{0.15} \mathrm{Cl}_{6}$ as a function of sample thickness at an X-ray photon energy of $22 \mathrm{keV}$. To unify the absorbed X-ray energies of these two kinds of scintillator, a $\mathrm{Cs}_{2} \mathrm{Ag}_{0.6^{-}}$ $\mathrm{Na}_{0.4} \mathrm{In}_{0.85} \mathrm{Bi}_{0.15} \mathrm{Cl}_{6}$ wafer with a 0.4-mm thickness and a LuAG:Ce wafer with a $0.11-\mathrm{mm}$ thickness were compressed. Then, the scintillator wafers were closely attached to the circular window of an integrating sphere with a fixed distance to the X-ray source, and the corresponding RL spectra were recorded by a QE PRO fibrecoupled fluorescence spectrometer (carefully calibrated by an Ocean Optics engineer before usage). Comparing the integrated intensities of the two spectra, a light yield of $39,000 \pm 7000$ photons $/ \mathrm{MeV}$ for the $\mathrm{Cs}_{2} \mathrm{Ag}_{0.6^{-}}$ $\mathrm{Na}_{0.4} \mathrm{In}_{0.85} \mathrm{Bi}_{0.15} \mathrm{Cl}_{6}$ scintillator was acquired. The measurement system was cross-checked with another commercial scintillator of CsI:TI, obtaining a light yield of 57,000 photons $/ \mathrm{MeV}$, which matches its datasheet value $(\sim 60,000$ photons $/ \mathrm{MeV})$ and proves the validity of the measurement method.

\section{X-ray imaging optical system setup}

A Mini-X X-ray tube (target material: $\mathrm{Ag}, P_{\max }=4 \mathrm{~W}$, $V_{\max }=50 \mathrm{kV}, I_{\max }=79 \mu \mathrm{A}$ ) produced by Amptek Inc. was utilised as the $\mathrm{X}$-ray source, generating an X-ray output spectrum with both intense characteristic radiation of $\mathrm{Ag}$ and broad bremsstrahlung radiation. The average X-ray photon energy was $\sim 22 \mathrm{keV}$. The X-ray dose rates were altered by adjusting the current of the $\mathrm{X}$-ray tube from $5 \mu \mathrm{A}$ to $79 \mu \mathrm{A}$, and were calibrated by a highly sensitive $\mathrm{X}$-ray ion chamber dose meter (Radcal Corporation $10 \times 5-180)$. The objects and scintillator wafers were placed vertically to the incident X-rays, and the scintillators were fixed just behind the objects. A reflector was utilised to deflect the optical path by $90^{\circ}$ to diminish the negative influence caused by direct radiation from the X-ray source on the camera. To collect X-ray images, a CMOS camera (Photometrics 95B) with $1200 \times$ 1200 pixels and a $11-\mu \mathrm{m}$ pixel size was equipped.

\section{MTF measurements}

MTF represents the capability to transfer the input signal modulation at a given spatial frequency to its output, and can be used to evaluate the fundamental spatial resolution performance of an imaging system. The spatial resolution can be determined by the spatial frequency value when $\mathrm{MTF}=0.2$. The MTF curve was calculated by the slanted-edge method. First, a piece of aluminium (thickness: $\sim 1 \mathrm{~mm}$ ) with a sharp edge was placed on the scintillator, and its edge profile was derived from the resulting X-ray image. Then, the edge spread function (ESF) was derived from the edge profile, from which we could deduce the line spread function (LSF). Finally, the MTF values were defined by the Fourier transform of the LSF as follows:

$$
\operatorname{MTF}(v)=F(\operatorname{LSF}(x))=F\left(\frac{\operatorname{dESF}(x)}{\mathrm{d} x}\right),
$$

where $v$ is the spatial frequency, and $x$ is the position of the pixels. 


\section{Acknowledgements}

The authors acknowledge the support from the National Key Research and Development Program of China (2017YFA0207700), Outstanding Youth Fund of Zhejiang Natural Science Foundation of China (LR18F050001) and National Natural Science Foundation of China (61804134, 61525106, U1809204). The authors would also like to thank Mr. Yufen Han and Mr. Suilao Yao of the Beijing Hamamatsu Photonics for their helpful discussions.

\section{Author contributions}

Y.(M.)Y. conceived the idea and supervised the project. Y.(M.)Y., W.Z. and W.M. designed the experiments. W.Z. carried out material preparation and characterisations. W.M., Y.(M.)Y. and Y.M. set up the X-ray imaging system. W.M. and W.Z. measured the scintillator property and implemented the $X$-ray imaging experiments. Z.C. conducted the PL-decay measurement. Y.S. and X.C. assisted the X-ray imaging experiments. W.X. and X.L. helped in the PLQY measurement. L.B. and T.L. assisted the compressing of wafers and absorption spectra measurement. W.Z. wrote the first draft of the paper and Y.(M.)Y. revised the paper with comments from X.L., H.L. and all other authors.

\section{Conflict of interest}

The authors declare that they have no conflicts of interest.

Supplementary information is available for this paper at https://doi.org/ 10.1038/s41377-020-00353-0.

Received: 6 March 2020 Revised: 12 June 2020 Accepted: 17 June 2020 Published online: 30 June 2020

\section{References}

1. Chen, Q. S. et al. All-inorganic perovskite nanocrystal scintillators. Nature $\mathbf{5 6 1}$, 88-93 (2018).

2. Heo, J. H. et al. High-performance next-generation perovskite nanocrystal scintillator for nondestructive X-ray imaging. Adv. Mater. 30, 1801743 (2018).

3. Zhang, Y. H. et al. Metal halide perovskite nanosheet for X-ray highresolution scintillation imaging screens. ACS Nano 13, 2520-2525 (2019).

4. Wang, L. L. et al. Ultra-stable $\mathrm{CsPbBr}_{3}$ perovskite nanosheets for $\mathrm{X}$-ray imaging screen. Nano-Micro Lett. 11, 52 (2019).

5. Cao, F. et al. Shining emitter in a stable host: design of halide perovskite scintillators for X-ray imaging from commercial concept. ACS Nano $\mathbf{1 4}$ 5183-5193 (2020)

6. Kim, Y. C. et al. Printable organometallic perovskite enables large-area, lowdose X-ray imaging. Nature 550, 87-91 (2017)

7. Van Eijk, C. W. E. Inorganic scintillators in medical imaging. Phys. Med. Biol. 47, R85-R106 (2002).

8. Chapman, H. N. et al. Femtosecond X-ray protein nanocrystallography. Nature 470, 73-77 (2011).

9. Lecoq, P. Development of new scintillators for medical applications. Nud. Instrum. Methods Phys. Res. Sect. A: Accelerators, Spectrometers, Detect. Associated Equip. 809, 130-139 (2016).

10. Rabin, O. et al. An X-ray computed tomography imaging agent based on long-circulating bismuth sulphide nanoparticles. Nat. Mater. 5, 118-122 (2006).

11. Spahn, M. X-ray detectors in medical imaging. Nucl. Instrum. Methods Phys. Res. Sect. A: Accelerators, Spectrometers, Detect. Associated Equip. 731, 57-63 (2013).

12. Rowlands, J. A. Material change for X-ray detectors. Nature 550, 47-48 (2017).

13. Yaffe, M. J. \& Rowlands, J. A. X-ray detectors for digital radiography. Phys. Med. Biol. 42, 1-39 (1997)

14. Greskovich, C. \& Duclos, S. Ceramic scintillators. Annu. Rev. Mater. Sci. 27, 69-88 (1997).

15. Büchele, P. et al. X-ray imaging with scintillator-sensitized hybrid organic photodetectors. Nat. Photonics 9, 843-848 (2015).

16. Wang, Z. G. et al. Kinetic Monte Carlo simulations of excitation density dependent scintillation in Csl and CSI (TI). Phys. Status Solidi B 250, 1532-1540 (2013).
17. Nillius, P. et al. Light output measurements and computational models of microcolumnar Csl scintillators for x-ray imaging. Med. Phys. 42, 600-605 (2015).

18. $\mathrm{Xu}$, J. et al. Fabrication, microstructure, and luminescent properties of $\mathrm{Ce}^{3}$ ${ }^{+}$-Doped $\mathrm{Lu}_{3} \mathrm{Al}_{5} \mathrm{O}_{12}(\mathrm{Ce}: \mathrm{LuAG})$ transparent ceramics by low-temperature vacuum sintering. J. Am. Ceram. Soc. 96, 1930-1936 (2013).

19. Yakunin, $\mathrm{S}$. et al. Detection of X-ray photons by solution-processed lead halide perovskites. Nat. Photonics 9, 444-449 (2015).

20. Shrestha, S. et al. High-performance direct conversion X-ray detectors based on sintered hybrid lead triiodide perovskite wafers. Nat. Photonics 11, 436-440 (2017).

21. Kawano, N. et al. Scintillating organic-inorganic layered perovskite-type compounds and the gamma-ray detection capabilities. Sci. Rep. 7, 14754 (2017)

22. Wei, W. et al. Monolithic integration of hybrid perovskite single crystals with heterogenous substrate for highly sensitive X-ray imaging. Nat. Photonics 11, 315-321 (2017).

23. Birowosuto, M. D. et al. X-ray scintillation in lead halide perovskite crystals. Sci. Rep. 6, 37254 (2016).

24. Wang, $X$. et al. PIN diodes array made of perovskite single crystal for $X$-ray imaging. Phys. Status Solidi RRL 12, 1800380 (2018).

25. Liu, J. Y. et al. Flexible, printable soft-X-ray detectors based on all-inorganic perovskite quantum dots. Adv. Mater. 31, 1901644 (2019).

26. Mykhaylyk, V. B., Kraus, H. \& Saliba, M. Bright and fast scintillation of organolead perovskite $\mathrm{MAPbBr}_{3}$ at low temperatures. Mater. Horiz. 6, 1740-1747 (2019).

27. Jiang., T. M. et al. Power conversion efficiency enhancement of low-bandgap mixed $\mathrm{Pb}$-Sn perovskite solar cells by improved interfacial charge transfer. ACS Energy Lett. 4, 1784-1790 (2019).

28. Gao., Y. et al. Highly stable lead-free perovskite field-effect transistors incorporating linear $\pi$-conjugated organic ligands. J. Am. Chem. Soc. 141, 15577-15585 (2019)

29. Jiang., T. M. et al. Realizing high efficiency over $20 \%$ of low-bandgap Pb-Snalloyed perovskite solar cells by in situ reduction of $\mathrm{Sn}^{4+}$. Sol. RRL 4, 1900467 (2020).

30. Yang, B. et al. Lead-free direct band gap double-perovskite nanocrystals with bright dual-color emission. J. Am. Chem. Soc. 140, 17001-17006 (2018).

31. Luo, J. J. et al. Efficient and stable emission of warm-white light from lead-free halide double perovskites. Nature 563, 541-545 (2018).

32. Volonakis, $\mathrm{G}$. et al. $\mathrm{Cs}_{2} \ln \mathrm{AgCl}$ : a new lead-free halide double perovskite with direct band gap. J. Phys. Chem. Lett. 8, 772-778 (2017).

33. Yang, B. et al. Lead-free halide $\mathrm{Rb}_{2} \mathrm{CuBr}_{3}$ as sensitive X-ray scintillator. Adv. Mater. 31, 1904711 (2019).

34. Lin, R. C. et al. All-inorganic $\mathrm{CsCu}_{2} \mathrm{l}_{3}$ single crystal with high-PLQY $(\approx 15.7 \%)$ intrinsic white-light emission via strongly localized 1D excitonic recombination. Adv. Mater. 31, 1905079 (2019).

35. Jun, $\mathrm{T}$. et al. Lead-free highly efficient blue-emitting $\mathrm{Cs}_{3} \mathrm{Cu}_{2} \mathrm{I}_{5}$ with $\mathrm{OD}$ electronic structure. Adv. Mater. 30, 1804547 (2018).

36. Xie, J. L. et al. New lead-free perovskite $\mathrm{Rb}_{7} \mathrm{Bi}_{3} \mathrm{Cl}_{16}$ nanocrystals with blue luminescence and excellent moisture-stability. Nanoscale 11, 6719-6726 (2019).

37. McCall, K. M. et al. From $\mathrm{OD} \mathrm{Cs}_{3} \mathrm{Bi}_{2} \mathrm{l}_{9}$ to $2 \mathrm{D} \mathrm{Cs}_{3} \mathrm{Bi}_{2} \mathrm{I}_{6} \mathrm{Cl}_{3}$ : dimensional expansion induces a direct band gap but enhances electron-phonon coupling. Chem. Mater. 31, 2644-2650 (2019)

38. Ding, N. et al. Europium-doped lead-free $\mathrm{Cs}_{3} \mathrm{Bi}_{2} \mathrm{Br}_{9}$ perovskite quantum dots and ultrasensitive $\mathrm{Cu}^{2+}$ detection. ACS Sustain. Chem. Eng. 7, 8397-8404 (2019).

39. $\mathrm{Hu}, \mathrm{Q}$. S. et al. X-ray scintillation in lead-free double perovskite crystals. Sci. China Chem. 61, 1581-1586 (2018).

40. Slavney, A. H. et al. A bismuth-halide double perovskite with long carrier recombination lifetime for photovoltaic applications. J. Am. Chem. Soc. 138 2138-2141 (2016)

41. Steele, J. A. et al. Photophysical pathways in highly sensitive $\mathrm{Cs}_{2} \mathrm{AgBiBr}_{6}$ double-perovskite single-crystal X-ray detectors. Adv. Mater. 30, 1804450 (2018).

42. Pan, W. C. et al. $\mathrm{Cs}_{2} \mathrm{AgBiBr}_{6}$ single-crystal $\mathrm{X}$-ray detectors with a low detection limit. Nat. Photonics 11, 726-732 (2017).

43. Meng, W. W. et al. Parity-forbidden transitions and their impact on the optical absorption properties of lead-free metal halide perovskites and double perovskites. J. Phys. Chem. Lett. 8, 2999-3007 (2017).

44. Han, P. G. et al. Size effect of lead-free halide double perovskite on luminescence property. Sci. China Chem. 62, 1405-1413 (2019). 
45. $\mathrm{Hu}, \mathrm{Q}$. S. et al. Tunable color temperatures and efficient white emission from $\mathrm{CS}_{2} \mathrm{Ag}_{1-x} \mathrm{Na}_{x} \mathrm{nn}_{1-y} \mathrm{Bi}_{y} \mathrm{Cl}_{6}$ double perovskite nanocrystals. Small 15, 1903496 (2019).

46. Zhou, J. et al. Manipulation of $\mathrm{Bi}^{3+} / \mathrm{In}^{3+}$ transmutation and $\mathrm{Mn}^{2+}$-doping effect on the structure and optical properties of double perovskite $\mathrm{Cs}_{2} \mathrm{NaBi}_{1}$. ${ }_{x} \mathrm{n}_{*} \mathrm{Cl}_{6}$. Adv. Optical Mater. 7, 1801435 (2019).

47. Blasse, G. Scintillator materials. Chem. Mater. 6, 1465-1475 (1994).

48. Grim, J. Q. et al. The roles of thermalized and hot carrier diffusion in determining light yield and proportionality of scintillators. Phys. Status Solidi A 209 2421-2426 (2012).
49. Samei, E., Flynn, M. J. \& Reimann, D. A. A method for measuring the presampled MTF of digital radiographic systems using an edge test device. Med. Phys. 25, 102-113 (1998).

50. Kabir, M. Z. Effect of repeated $x$-ray exposure on the resolution of amorphous selenium based x-ray imagers. Med. Phys. 37, 1339-1349 (2010).

51. Yasuda, R., Katagiri, M. \& Matsubayashi, M. Influence of powder particle size and scintillator layer thickness on the performance of $\mathrm{Gd}_{2} \mathrm{O}_{2} \mathrm{~S}: \mathrm{Tb}$ scintillators for neutron imaging. Nucl. Instrum. Methods Phys. Res. Sect. A: Accelerators, Spectrometers, Detect. Associated Equip. 680, 139-144 (2012). 